\title{
Photogrammetry in maritime and underwater archaeology: two marble wrecks from Sicily
}

\author{
C. Ballettia , C. Beltrame ${ }^{\mathrm{b}}$, E. Costa ${ }^{\mathrm{a}}$, F. Guerra ${ }^{\mathrm{a}}$, P. Vernier ${ }^{\mathrm{a}}$ \\ ${ }^{a}$ Università Iuav di Venezia, S. Croce 191, 30135 Venezia, Italy* \\ 'Università Ca' Foscari Venezia, Dorsoduro 3484/D, 30123 Venezia, Italy**
}

\begin{abstract}
Underwater survey, compared to land archaeology, needs some specific techniques, because the application of some active 3D sensor, such as laser scanner, is obviously impossible. The necessity to produce three-dimensional survey, offering the same accuracy of classical terrestrial laserscanning or photogrammetric methods, combined with the request of low costs and rapid solutions, led the researchers to test and apply oftentimes image-based techniques.

In the last two years the Ca' Foscari University and University IUAV of Venice are conducting a research on the application of integrated techniques to support underwater metric documentation, comparing them to the manual traditional one. The gained experience (and confirmed by other recently published papers) shows that the actual multiimage digital photogrammetry is a good solution for the underwater archaeology. This approach is useful both from a metric and from a recording point of view, because it achieves high quality results, such as accurate 3D models or 2D representations, offering a complete documentation of underwater sites.

But photogrammetry has to be supported by a topographical survey (to acquire ground control points - GCP) to georeference all the finds in the same reference system. This paper presents the integrated survey of two roman shipwrecks, approaching differently in the GCP's acquisition just for the different morphological characteristic of the sites. The wrecks' cargos are huge marble blocks, presenting differences in quantities, layout and depths. Those characteristics determine the choice of the topographic survey.

The results of the survey are two 3D polygonal textured models of the sites, which can be easily used for different analyses and reconstructive hypothesis, opening new possibilities of documentation with both specialists and the wider public. Furthermore, 3D models are the geometric base for 2D orthophoto and cross section extraction.

The paper will illustrate all the phases regarding the survey's design, acquisition and realization and the data processing to obtain 2D and 3D final representation.
\end{abstract}

Keywords: Shipwreck, Maritime archaeology, Marble, Underwater multi-image photogrammetry, 3D modelling, GPS

\section{INTRODUCTION}

The use of photogrammetry in underwater archaeology has long been a good tradition, since 1960-70's with the first underwater stereo-pairs cameras ${ }^{1-5}$. Parallel optical axes in accordance with required stereo-vision conditions and high degree of technical knowledge are some of the disadvantages imposed by this method.

The necessity to reduce the time of underwater work for hyperbaric reasons, especially in deeper sites, has driven the researchers to transfer the work to post-processing activity, looking for a fast techniques of documentation. In the same time, these techniques should be low-cost and accessible, considering the not large budgets of the discipline ${ }^{6}$. Multiimage photogrammetry combine these characteristics to the necessity to produce detailed and accurate three-dimensional mapping, peculiarity of the stereo-photogrammetric technique $e^{7-9,6,10}$.

This technique has demonstrated, on land, to offer a very realistic image of the site and to be very precise and easy to use $^{11}$; also underwater, this kind of approach is recognized as a powerful and accessible tool for no-destructive archaeology all around the world ${ }^{12}$. Over the last few years, photogrammetry has received a great stimulus by various projects of research and many experimentation were made to capture 3D models of underwater archaeological features using simple single cameras - and not double photogrammetric cameras - operated by a diver, without the use of frames, and processing the data with special softwares in very automated ways ${ }^{13}$.

Ca' Foscari University and University IUAV of Venice are conducting a research on the application underwater of the multi-image photogrammetry integrated with topographic survey to support metric documentation. Recent studies ${ }^{14-18}$ confirm that, at the moment, multi-image photogrammetry is a good technique for mapping and recovering the shape and

* (balletti, ecosta, guerra2, vernier)@iuav.it

** beltrame@unive.it

Optics for Arts, Architecture, and Archaeology V, edited by Luca Pezzati, Piotr Targowski, Proc. of SPIE Vol. 9527, 95270M · (c) 2015 SPIE · CCC code: 0277-786X/15/\$18 · doi: 10.1117/12.2184802 
geometry of objects completely submerged. It has transformed underwater photogrammetry from a highly technical and costly process to an accessible tool ${ }^{13}$.

The present paper wants to describe the method employed on two shipwrecks in 2014, with images acquisition, topographic measure and data processing to gain 2D drawing and 3D model of the archaeological sites. The production of a precise 3D model offers many opportunities both from a metric and from a recording point of view, because it represents a faithful model. It is possible to virtually "return" to the site to verify many kinds of data: measures, shapes, colours, locations etc. ${ }^{19}$.

\section{THE ARCHAEOLOGICAL CONTEXT}

Aim of the work is the implementation of a technique of 3D underwater documentation with multi-image photogrammetric recording. Good cases study to begin this work were identified on some cargos composed of blocks of marble sunk at low depth and in a good visibility context along the coast of Sicily.

The investigation of this photogrammetric technique starts some years ago, in South Italy, in Crotone, where we realized a previous experiment only to test the perspectives of research of a 3D representation model from points clouds. This was only a test because is made using some images not realized for a $3 \mathrm{D}$ final representation but only for a simple photomosaic (figure 1). We want to show the employ of software and hardware that can automatically perform camera self-calibration and offer the possibility to use several cameras and sensors to obtain dense points clouds or 3D models suitable for different fields of application.

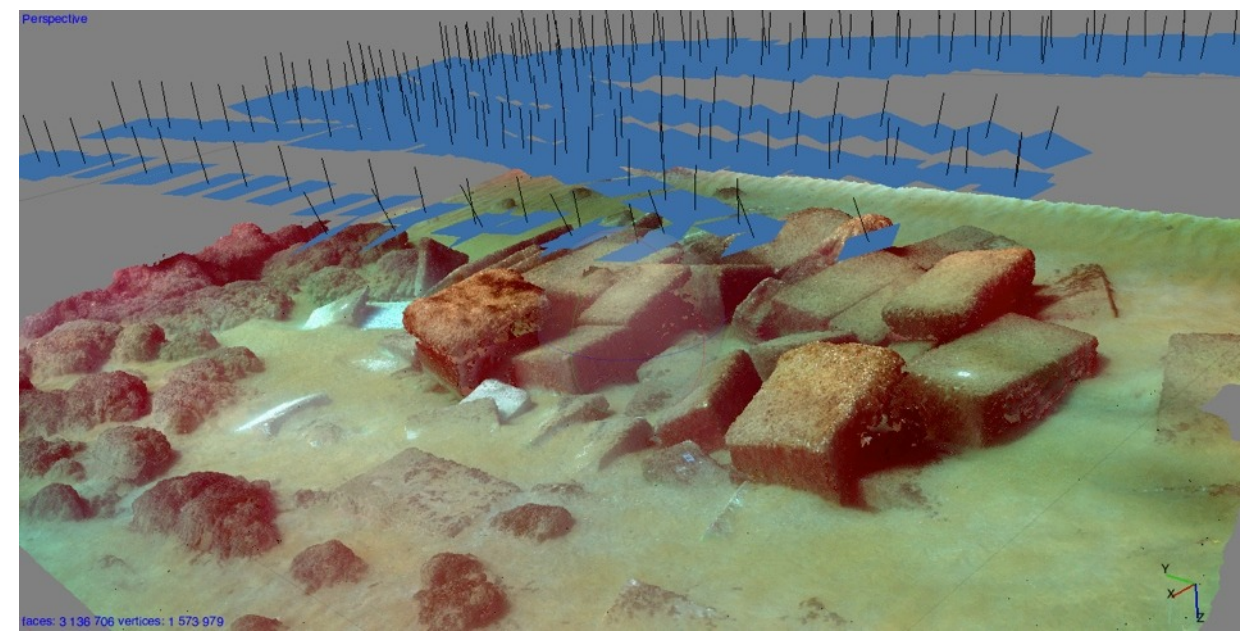

Figure 1. Punta Scifo D shipwreck. Camera alignment and points cloud

In 2014 the department of Studi Umanistici of Ca' Foscari University, coordinated by the maritime archaeologist Carlo Beltrame, in collaboration with Circe Laboratory of Photogrammetry of IUAV University of Architecture of Venice, coordinated by Francesco Guerra, and the Soprintendenza del Mare of the Regione Sicilia, has investigated two shipwrecks of cargos of marble blocks dated at the Roman age.

The integrated survey realized on these shipwrecks, which are different for morphological characteristic of the sites, develops in these phases:

- cleaning of the subject from sand and vegetation;

- manual tape measurements and detail photographs of the marble blocks;

- laying of markers (GCP) on the upper surfaces of the marble blocks;

- images acquisition for multi-image digital photogrammetry;

- topographic survey of the GCP, with trilateration (Direct Survey Method) and GPS RTK's measurement;

- 3D reconstruction. 


\subsection{Case study 1: Marzamemi I shipwreck}

The first shipwreck, off Marzamemi (Siracusa) in southeast Sicily, was discovered in 1958 by fishermen and in 1959 was documented with a first survey and some photographs by G. Kapitaen and P.N. Gargallo. G. Kapitaen dated the site at 3 rd century A.D., according to the study of two types of amphoras ${ }^{20}$.

Actually, the site is composed by 14 white marble blocks, positioned scattered on the seabed; the surfaces of the blocks are irregular and degraded, but it is possible to recognize big columns and squared blocks (figure 2).

The principal cluster is composed by 9 semi-finished item:

- 3 big squared blocks, the biggest measures $215 \times 168 \times 114(\mathrm{~h}) \mathrm{cm}$;

-3 big columns, with a maximum length of $595 \mathrm{~cm}$ and a diameter of $138 \mathrm{~cm}$;

- 1 big irregular block, with a maximum length of $343 \mathrm{~cm}$;

- 3 little parallelepiped blocks.

The other four blocks are far from the main cluster:

- $15 \mathrm{~m}$ south there is the biggest column of the site and the biggest column found underwater in the Mediterranean. It measures $640 \times 185 \mathrm{~cm}$ and it weighs 49 tons;

- $15 \mathrm{~m}$ south-west there are 2 medium blocks overlapping between them;

- $32 \mathrm{~m}$ west there is another column.

The total tonnage, calculated on a specific gravity of $2.68 \mathrm{gr}$, is 164 tons, with a total volume of $61 \mathrm{~m}^{3}$.
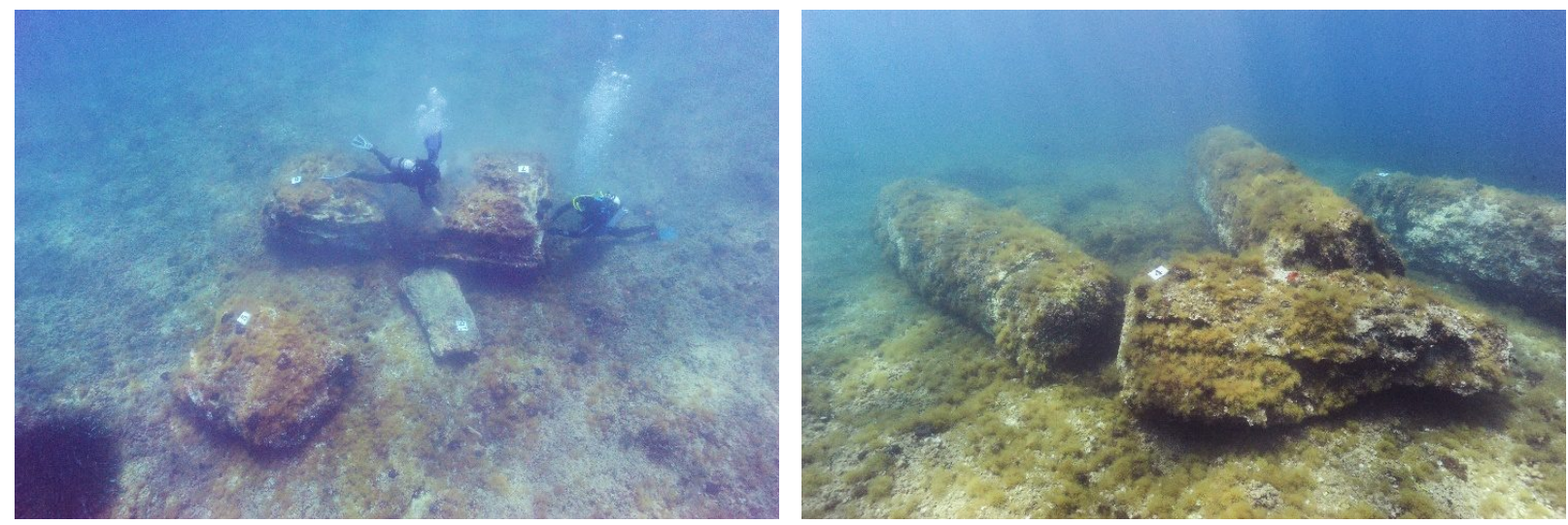

Figure 2. Marzamemi I shipwreck. Three squared blocks (on the left), three columns and one irregular block (on the right) of the main cluster. (photo: Duilio Della Libera)

\subsection{Case study 2: Cape Granitola shipwreck}

The second shipwreck, near Granitola (Mazara del Vallo-Trapani) in south-west Sicily, was documented with a first survey in 1976 by G. Purpura and then by Poseidon private company which made a simple bi-dimensional plan. The shipwreck is dated in the 3rd century A.D.

The shipwreck lies at $3 \mathrm{~m}$ under the sea level and it is only $200 \mathrm{~m}$ off the shore; it is represented by an homogeneous cargo, found in stowage position, on parallel lines, of 63 squared marble blocks and 2 (or perhaps 3) podia (figure 3).

The marble blocks are corroded and concretionated but are cut squared in various dimensions, with length from 60 to $330 \mathrm{~cm}$.

Some of them are broken but the coherent position gives the possibility to virtually re-gather them.

We made a rapid calculation of the tonnage, realized on the maximum measure (length, width and high) of the visible blocks and the tonnage is about 150 tons. This consideration could be validated only after the excavation of all site, because some of the block are even now hide by seaweeds and sand.

Archaeometric analysis made by Lorenzo Lazzarini (LAMA, University IUAV of Venice) on only few samples have preliminary proposed proconnesion marble, from Marmara Sea. 

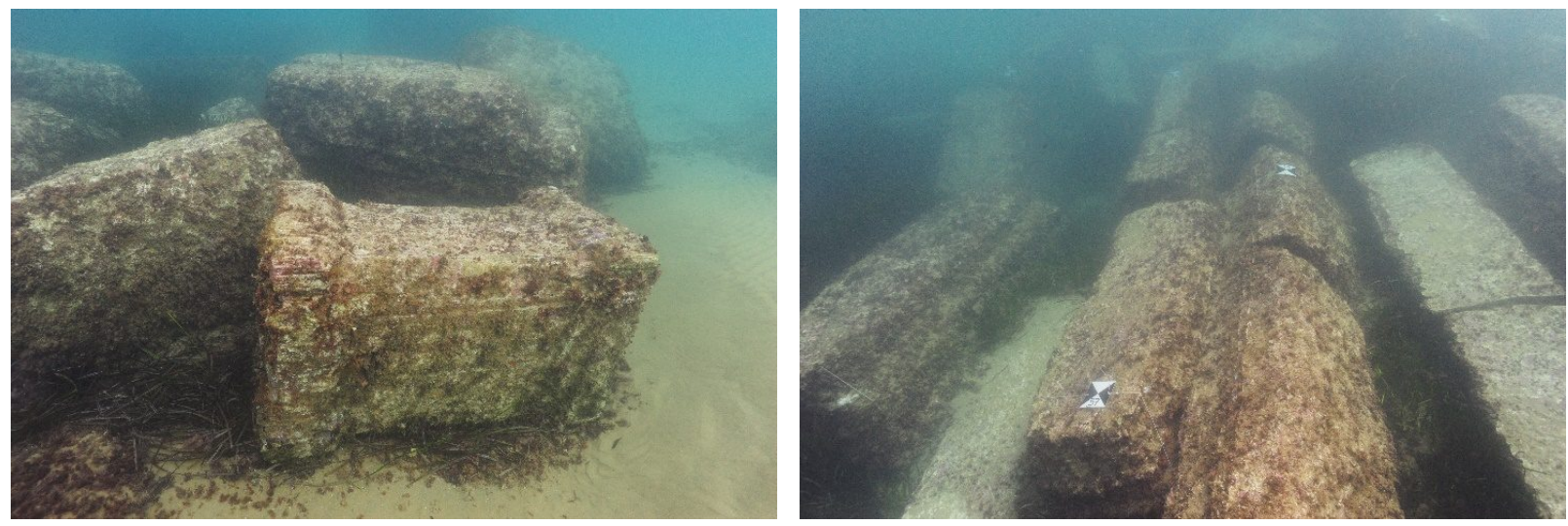

Figure 3. Cape Granitola shipwreck. One of the two podia (on the left) and part of the cargo in stowage position on parallel lines (on the right). (photo: Duilio Della Libera)

\section{REALITY BASED 3D DOCUMENTATION}

\subsection{Image based survey}

In the last year, photogrammetry seems to be revived as a competitive technology, thanks to some significant progress in hardware and innovative image-matching algorithms ${ }^{21}$, so image-based surveying and 3D modelling can now offer, in reasonable time, results comparable to those of laser scanning (range based survey) for many terrestrial and aerial applications.

Nowadays image-based measurement tools allow obtaining, in the field of cultural heritage documentation and recording, 3D realistic models to be used in several application, with a particular interest from the archaeological point of view.

There are many software and hardware solutions proposed in order to reduce the costs of instruments (i.e. low cost consumer digital cameras), times in acquisition and processing without requiring trained personnel. The image-based techniques, using algorithms derived from Computer Vision, such as the well-known Structure from Motion and Dense Multi View 3D Reconstruction ${ }^{22,6}$, are able to automatically perform the whole pipeline reducing time both of images orientation and of $3 \mathrm{D}$ reconstruction ${ }^{23}$.

Furthermore, we can work with a wide variety of multi-image photogrammetry software, such as Photomodeler, Agisoft Lens, iWitness, MicMac, 3DF Zephir, etc. ${ }^{22}$, that can automatically perform camera self-calibration and offer the possibility to use several cameras and sensors to obtain dense point clouds or 3D models suitable for different fields of application.

These instruments are widely used for 3D reconstructions of monuments, for the rigorous modelling of lands, cities or archaeological sites and underwater finds, by creating complex models. This complexity depends from both the high number of acquired and elaborated data (images) and the articulation of the documented shapes.

Considering the Sicilian underwater sites, a photogrammetric strip was realized by Duilio Della Libera for each shipwreck, as in aerial photogrammetry, taking care to obtain complete coverage with overlapping of the archaeological site. Usually, during the acquisition phase of the images, some external factors can create problems in producing the 3D survey: the variability of the light conditions, the turbidity of the water and the loss of colour with the increase of depth. Those elements can alter the texture information legible at the same point on an artefact; these conditions are overtaken with white balance or post-processing colour correction.

All the images - acquired, for the above-mentioned reasons, at the same dive - were aligned with Agisoft's Photoscan software (most papers describing the use of SfM in archaeology have focussed on the use of Photoscan which enables georeferencing and creation of textured models from the resulting point cloud and creation of digital elevation models) realizing a singlewide photogrammetric block. The system can offer precise measurement, but its accuracy is always related to the camera calibration.

It is well known that camera calibration has to be carried out in situ because of the extremely varying chemical and physical properties (salinity, temperature, density, etc.) of water, the medium the optical rays move across ${ }^{24-27}$. There are 
a number of approaches that may be used to obtain a system calibration, either as a series of components or as a whole and may include the refractive effects of the air-glass-water interfaces either explicitly or implicitly. But in these experiences we preceded differently because of the reduced depth of sites: so, in order to improve accuracy, the camera intrinsic parameters were preliminary calculated, because a simulation of the diving was previously done.

The calibration process was conducted entirely automatically in AgiSoft Lens, using some sets of photos of two checkerboards positioned on the bottom of a pool where the simulation was held. The estimated interior camera parameters (horizontal and vertical focal lengths, the coordinates of the principal point, the radial and tangential lens distortions in the Brown's model and the skew coefficient) were used later as initial parameters in Agisoft alignment process to better perform the system convergence.

As is well known, simulation can improve the data accuracy, but in the underwater calibration process, because the presence of one more media (water, air and glass), cannot use a simple function of the distortion as for standard calibration $^{27}$. Moreover, the effect of refraction (depending on a number of parameters such as depth, temperature and salinity) can cause unstable modelling effects, so the intrinsic parameters of a submerged camera change significantly in comparison to the primary values.

There are other changes that should be taken into consideration during a preparation of a data acquisition plan: the Focal Length is larger and the Field of View is decreased underwater, thus a smaller area will be covered by a photograph then in the air; the turbidity of the water that drastically reduces the overall image contrast, hence the accuracy in image point marking.

Photogrammetry was realized for each shipwreck in the same way as in aerial photogrammetry: in order to make spatial models, nadiral regular strips had to guarantee a complete coverage of the archaeological site with a suitable images footprint overlap, i.e. $60 \%$ between photos and $20 \%$ between the strips ${ }^{28}$.

For the two shipwrecks, we made two different photographic sets:

- on Marzamemi: nadiral photographs, only on direction E-W and oblique photographs at $45^{\circ}$ and almost $90^{\circ}$ around the site, to take the details of the blocks. The dispersion of the 14 elements on the seabed gave the possibility to turn around them;

- on Cape Granitola: nadiral photographs, on two directions N-S and E-W. The 65 blocks are close together and on a wide area, therefore a good system to take all the vertical side of the blocks is based on two directional series of photos. We made also oblique photos at $45^{\circ}$, but after computer processing these photos were removed, since the blue colour of the water column over the blocks created a blue point cloud on the surface of the blocks. Anyway, in this situation, nadiral photographs with a good overlap were enough to create the 3D model.

In our case studies, clear and shallow water, good light conditions and a high-quality white balance allowed a good chromatic result.
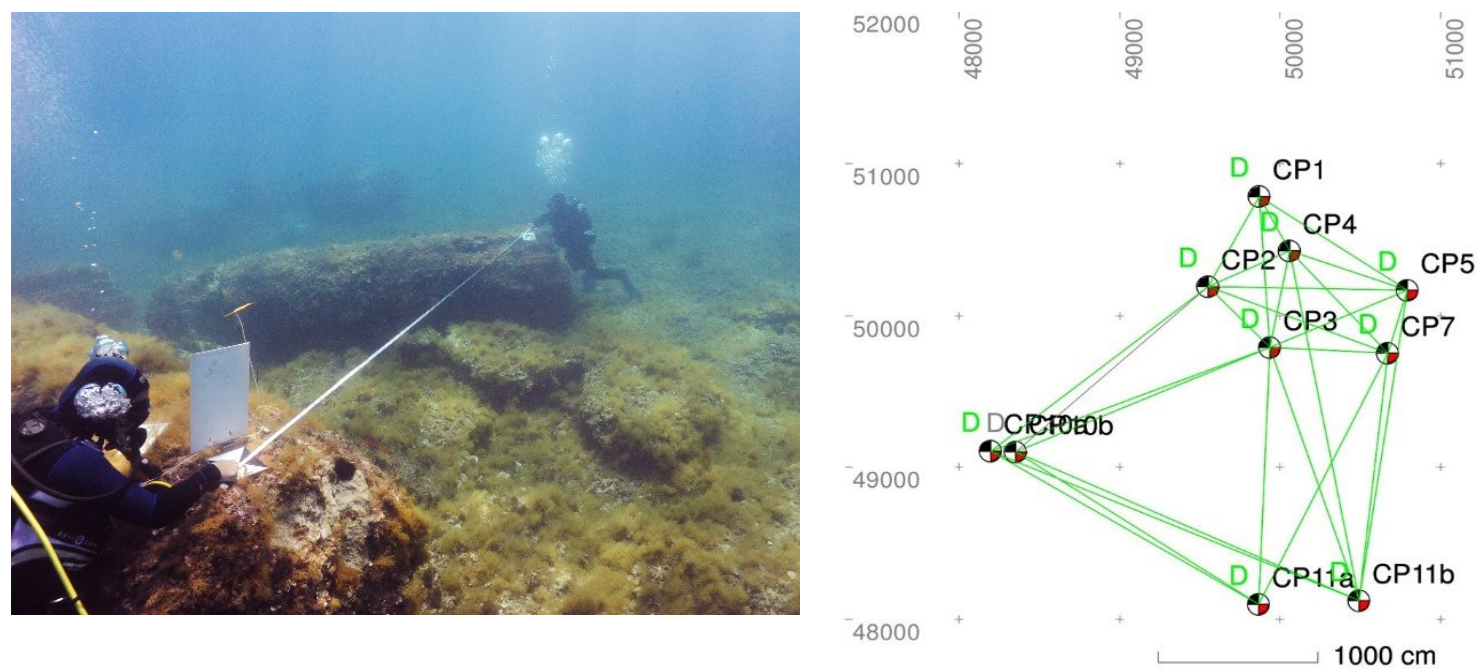

Figure 4. Marzamemi shipwreck I. Trilateration of GCP with linear direct measure between the numbered markers (on the left) and processing of the measure with Site Recorder software (on the right). 
For the photographs, we used a single digital camera Nikon D 700 with a $20 \mathrm{~mm}$ lens hosted in an underwater housing with a hemispheric dome. Resolution of the photographs is high-quality, 4256x2832 pixels, the ISO resolution at 1600. Depending on the sets of images, the F-stop is from 6.3 to 13 and the shutter from $1 / 250$ to $1 / 640 \mathrm{~s}$.

\subsection{Topographical survey}

To obtain an accuracy that can be suitable to the application field, photogrammetry has to be supported by a topographical survey (to acquire ground control points - GCP) to georeference all the finds in the same reference system. The wrecks cargos are huge marble blocks, presenting differences in quantities, layout and depths, so the GCP's acquisition has two different solutions.

The blocks on the site of Marzamemi are scattered on the seabed, some of them far from the principal cluster; this kind of distribution implicates a subdivision of the photogrammetric survey in four different clusters, added, at a later stage, in the same reference system with a trilateration method.

The realized trilateration of numbered markers, placed on the upper side of some blocks, has been computed as a 3D topographic network using rigorous Least Squares techniques, following the DSM (Direct Survey Method) technique ${ }^{29}$. The data were processed with Site Recorder software to create $\mathrm{x}, \mathrm{y}, \mathrm{z}$ coordinate of the markers (figure 4). The coordinates are in a relative local system, which can be then georeferenced by GPS' survey in the world system.

The coordinates were inserted in Photoscan, in correspondence to the markers and they were employed both to rototraslate the model in the right position and to check the position of the markers. The medium error resulted by the processing is $0,053 \mathrm{~m}$, which is tolerably low considering that the linear measure were taken with a measuring tape on variables distances from $4.30 \mathrm{~m}$ to $13 \mathrm{~m}$ for the main cluster and from $16.80 \mathrm{~m}$ to 35.45 for the three sets of blocks out of the principal site.

Table 1. Comparing of the coordinates calculated by Site Recorder and by Photoscan and results of the residual error.

\begin{tabular}{|c|c|c|c|c|c|c|c|c|c|c|}
\hline \multirow{2}{*}{$\begin{array}{c}\text { NR. } \\
\text { MARKER }\end{array}$} & \multicolumn{2}{|c|}{ COORDINATES DSM } & \multicolumn{2}{c|}{ COORDINATES PHOTOSCAN } & \multicolumn{2}{|c|}{ RESIDUAL ERROR } & RESIDUAL \\
\cline { 2 - 11 } & $\mathrm{X}$ & $\mathrm{Y}$ & $\mathrm{Z}$ & $\mathrm{X}$ & $\mathrm{Y}$ & $\mathrm{Z}$ & $\mathrm{X}$ & $\mathrm{Y}$ & $\mathrm{Z}$ & VETOR \\
\hline $10 \mathrm{a}$ & 481,965 & 491,063 & $-4,996$ & 481,879 & 491,073 & $-4,953$ & $-0,086$ & 0,010 & 0,042 & 0,097 \\
\hline $10 \mathrm{~b}$ & 483,540 & 491,030 & $-5,493$ & 483,592 & 491,050 & $-5,506$ & 0,051 & 0,021 & $-0,014$ & 0,057 \\
\hline $11 \mathrm{a}$ & 498,672 & 481,025 & $-4,701$ & 498,707 & 481,047 & $-4,748$ & 0,035 & 0,022 & $-0,047$ & 0,063 \\
\hline $11 \mathrm{~b}$ & 504,913 & 481,218 & $-5,000$ & 504,932 & 481,226 & $-5,037$ & 0,020 & 0,008 & $-0,037$ & 0,043 \\
\hline $11 \mathrm{c}$ & 498,672 & 481,025 & $-6,301$ & 498,725 & 481,068 & $-6,245$ & 0,053 & 0,043 & 0,056 & 0,088 \\
\hline $13 \mathrm{a}$ & 459,147 & 496,296 & $-5,322$ & 459,139 & 496,309 & $-5,368$ & $-0,008$ & 0,013 & $-0,047$ & 0,049 \\
\hline $13 \mathrm{c}$ & 459,147 & 496,296 & $-6,142$ & 459,120 & 496,314 & $-6,100$ & $-0,027$ & 0,018 & 0,042 & 0,053 \\
\hline $13 \mathrm{cc}$ & 460,332 & 497,845 & $-5,322$ & 460,336 & 497,859 & $-5,330$ & 0,004 & 0,014 & $-0,008$ & 0,016 \\
\hline $17 \mathrm{~b}$ & 481,969 & 493,152 & $-5,884$ & 481,981 & 493,099 & $-5,878$ & 0,012 & $-0,053$ & 0,006 & 0,055 \\
\hline CP1 & 498,743 & 507,809 & $-5,029$ & 498,755 & 507,806 & $-5,029$ & 0,011 & $-0,003$ & 0,000 & 0,012 \\
\hline CP2 & 495,565 & 501,879 & $-4,685$ & 495,556 & 501,874 & $-4,752$ & $-0,009$ & $-0,005$ & $-0,068$ & 0,069 \\
\hline CP3 & 499,382 & 497,899 & $-5,322$ & 499,374 & 497,843 & $-5,256$ & $-0,007$ & $-0,056$ & 0,066 & 0,087 \\
\hline CP5 & 507,949 & 501,678 & $-5,451$ & 507,926 & 501,661 & $-5,449$ & $-0,023$ & $-0,017$ & 0,002 & 0,028 \\
\hline CP7 & 506,712 & 497,548 & $-5,152$ & 506,687 & 497,533 & $-5,147$ & $-0,025$ & $-0,014$ & 0,005 & 0,029 \\
\hline & & & & & & & & MEDIUM ERROR & 0,053 \\
\hline
\end{tabular}

Just because in Cape Granitola the depth of the shipwreck is about $3 \mathrm{~m}$ under the sea level, markers applied on the blocks were surveyed by GPS RTK's measurements mounting the antenna on a 4 m pole (figure 5). 

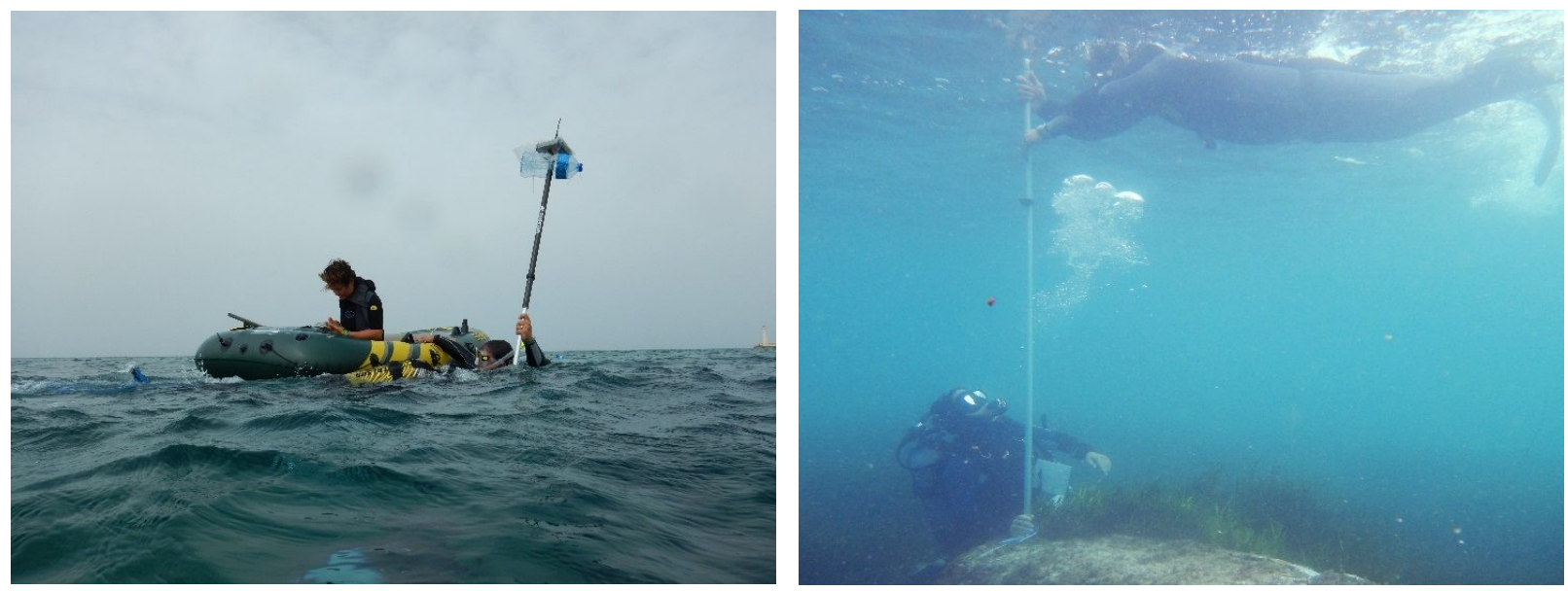

Figure 5. Cape Granitola shipwreck. Topographic measure of the GCP with the antenna mounted on a 4 meters pole.

Each marker was surveyed by repeated measurements: the movements of the pole are to be considered random, considering that its quite impossible to stay absolutely still in the water, and consequently also the position of the surveyed point can be random, then the barycentre of the acquired point cloud can be thought as the point lying on the vertical of the target. This statement is confirmed by some test runs carried out in the dry (figure 6) with the antenna on pole of 4 meters just like the ones used in Granitola. The master station was positioned on an IGM trigonometric point.
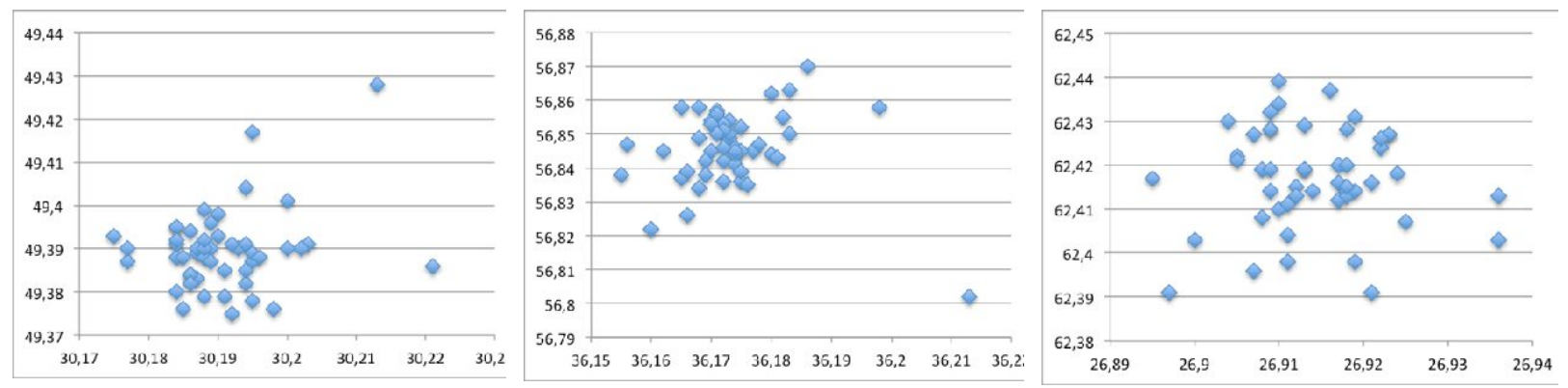

Figure 6. The random distribution of some surveyed GPS GCPs.

The dense point cloud coming from the photogrammetric block was referred to GPS GCP. However, some CGP were not used in the absolute orientation phase, but later as checkpoints in order to evaluate the final accuracy of the model, comparing the real dimension of the marble blocks and the measure coming from Photoscan software. The result is shown in the following table.

\section{3D RECONSTRUCTION}

3D modelling and representation of the underwater sites are a new kind of documentation in the latest years, which is still in fast development. The photogrammetry of Marzamemi shipwreck, as mentioned above, is subdivided in four chunks of photographs, due to the disposition of the cargo: 495 images were used for the complete survey, 323 images of these only for the main cluster of blocks. In the case studies of Cape Granitola shipwreck, 918 images were loaded to AgiSoft PhotoScan.

"Align photos" command computed the camera positions and their orientation; the images were aligned with a high accuracy and, in comparison to ancient stereo-photogrammetry, this process is totally automated. As result, a sparse 
point cloud model was produced.

At a later stage, the software created dense point clouds, to which triangulated meshes were applied. As a result of the survey, we have two 3D polygonal textured models of the sites, from which we have extrapolated some orthophotos from top viewpoint (figure 7) and some perspective views of the two shipwrecks (figure 8). The latest are useful for demonstration.

Table 2. Comparing table of the dimension calculated underwater and on Photoscan and result of the residual errors.

\begin{tabular}{|c|c|c|c|}
\hline NR. BLOCK & $\begin{array}{c}\text { REAL } \\
\text { MEASURE }\end{array}$ & $\begin{array}{l}\text { MEASURE } \\
\text { PHOTOSCAN }\end{array}$ & RESIDUAL \\
\hline 1a & 1,3 & 1,322 & $-0,022$ \\
\hline $1 \mathrm{c}$ & 0,55 & 0,537 & 0,013 \\
\hline 2 & 2,3 & 2,302 & $-0,002$ \\
\hline 3 & 1,6 & 1,497 & 0,103 \\
\hline 6 & 1,37 & 1,377 & $-0,007$ \\
\hline $7 \mathrm{a}$ & 1,33 & 1,332 & $-0,002$ \\
\hline $7 \mathrm{~b}$ & 0,8 & 0,817 & $-0,017$ \\
\hline 15 & 0,83 & 0,861 & $-0,031$ \\
\hline 21 & 1,3 & 1,303 & $-0,003$ \\
\hline 25 & 1,7 & 1,712 & $-0,012$ \\
\hline 29 & 0,6 & 0,556 & 0,044 \\
\hline 38 & 2,25 & 2,176 & 0,074 \\
\hline 47 & 1,5 & 1,559 & $-0,059$ \\
\hline 52 & 1,25 & 1,203 & 0,047 \\
\hline 53 & 3 & 2,992 & 0,008 \\
\hline 54 & 0,7 & 0,709 & $-0,009$ \\
\hline $54-55$ & 3,31 & 3,324 & $-0,014$ \\
\hline 56 & 2 & 1,941 & 0,059 \\
\hline 59 & 2,7 & 2,703 & $-0,003$ \\
\hline A-B & 13,8 & 13,86 & $-0,06$ \\
\hline C-D & 12 & 12,07 & $-0,07$ \\
\hline & \multicolumn{2}{|c|}{ MEDIUM RESIDUAL } & 0,034 \\
\hline
\end{tabular}
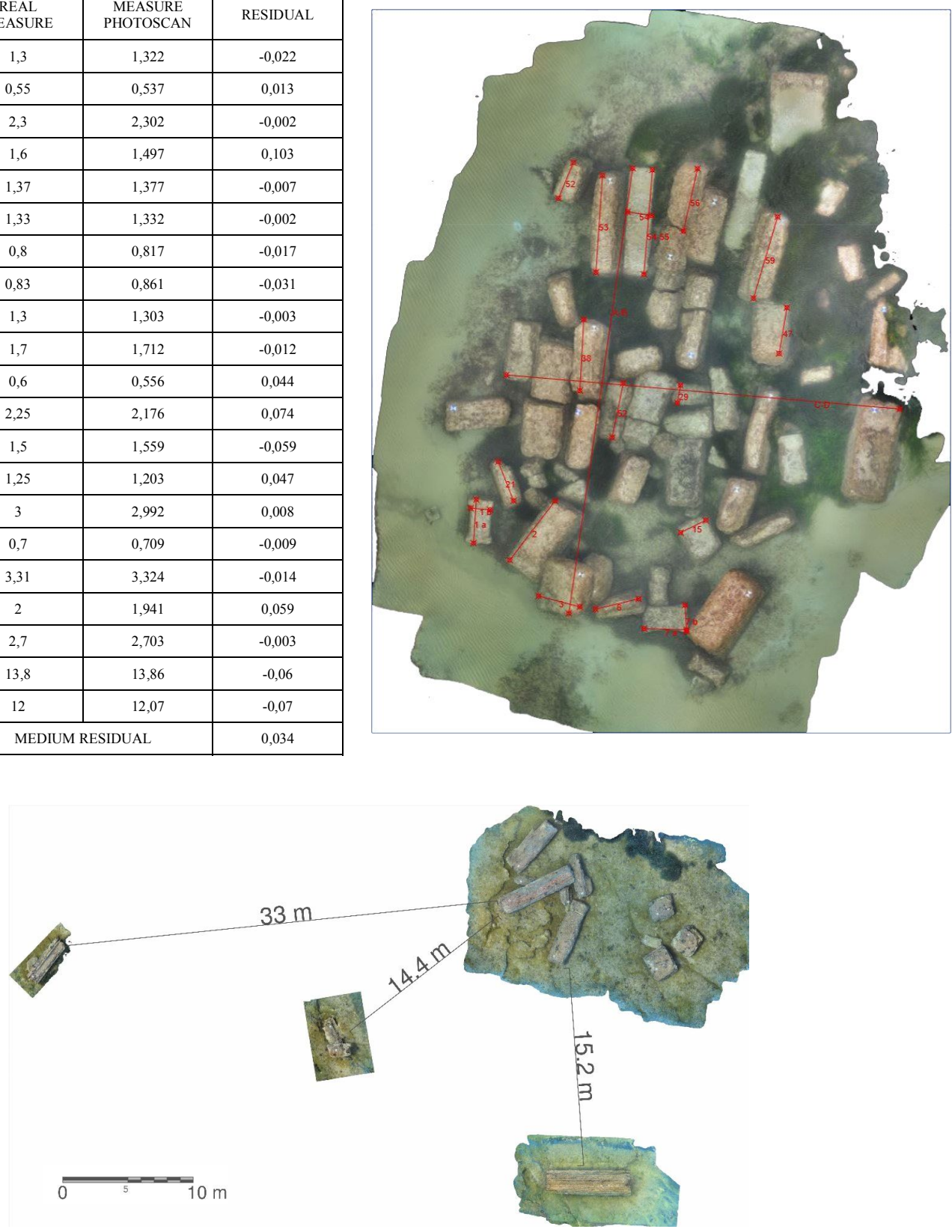

Figure 7. Orthophoto of Marzamemi I shipwreck. 

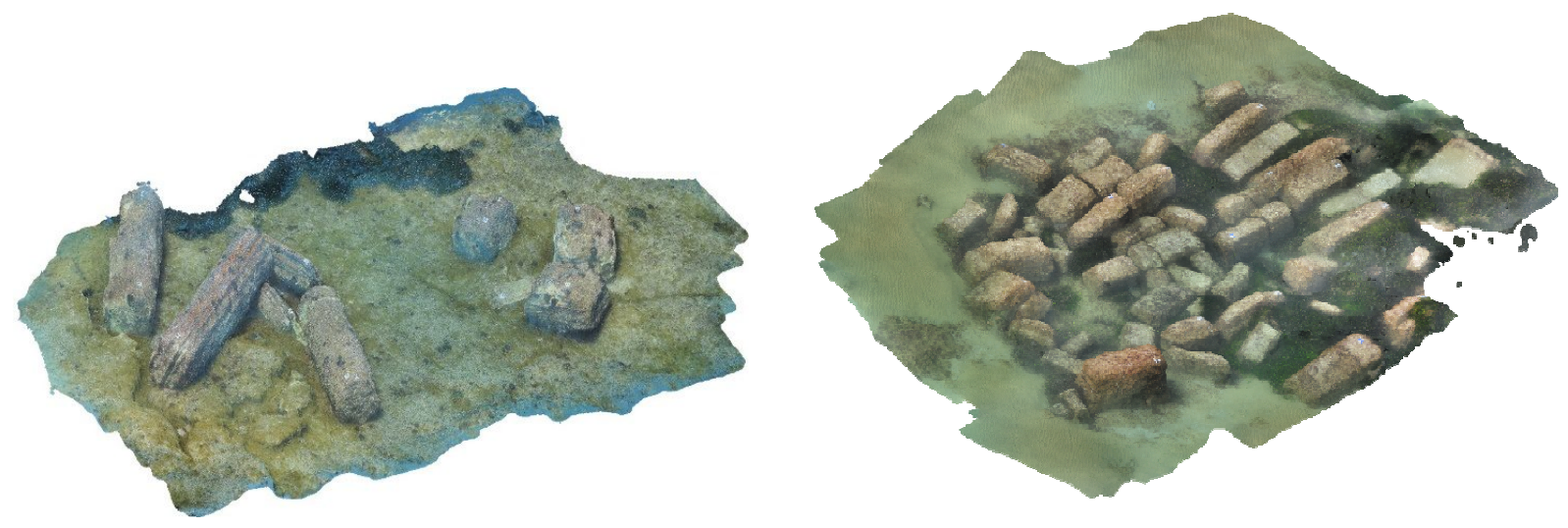

Figure 8. Perspective view of Marzamemi I shipwreck (on the left) and Cape Granitola shipwreck (on the right).

The textured model created by the software represents the marble blocks and the seabed; we have cleaned the model to highlight only the blocks, allowing direct elaborations on one single element, disconnected by the others.

The mesh of every single marble block was imported into a CAD program, where the elements were measured and compared with the dimensions taken underwater during the archaeological campaign. The final 3D model is then realized by removing the irregularity of the mesh, due to the concretions and the presence of seaweed. A portion of the blocks, the part close and in contact with the seabed was not visible during the images acquisition underwater and, consequently, on the model created by photogrammetry. This part has been integrated on 3D CAD software to recreate the original shape of the blocks (figure 9).

Textures of the marble applied on the model were based on the type of the marble detected by isotope analysis.

3D model can be employed for further use, for different analyses and reconstructive hypothesis, opening new possibilities of documentation with both specialists and the wider public (figure 10).
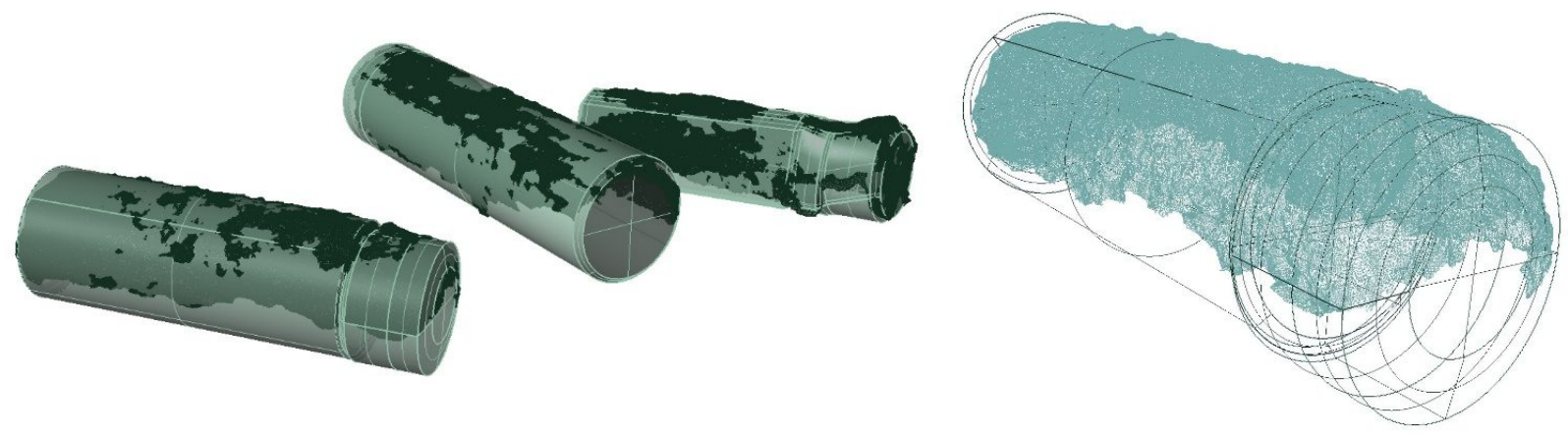

Figure 9. Marzamemi I shipwreck. Polygonal reconstruction on original mesh of the columns; ghosted view (on the left) and wireframe view (on the right).

The software has calculated also the precise volume both of every single item and of the entire cargo. Considering the specific gravity of the white marble and the volume, we have individuated the minimum tonnage of the cargos, on which it is possible hypothesize the reconstruction of the hull line of the two ships employed. The marble blocks were moved individually and rearranged on the correct position of stowage, based on hydrostatic calculations (figure 11). 

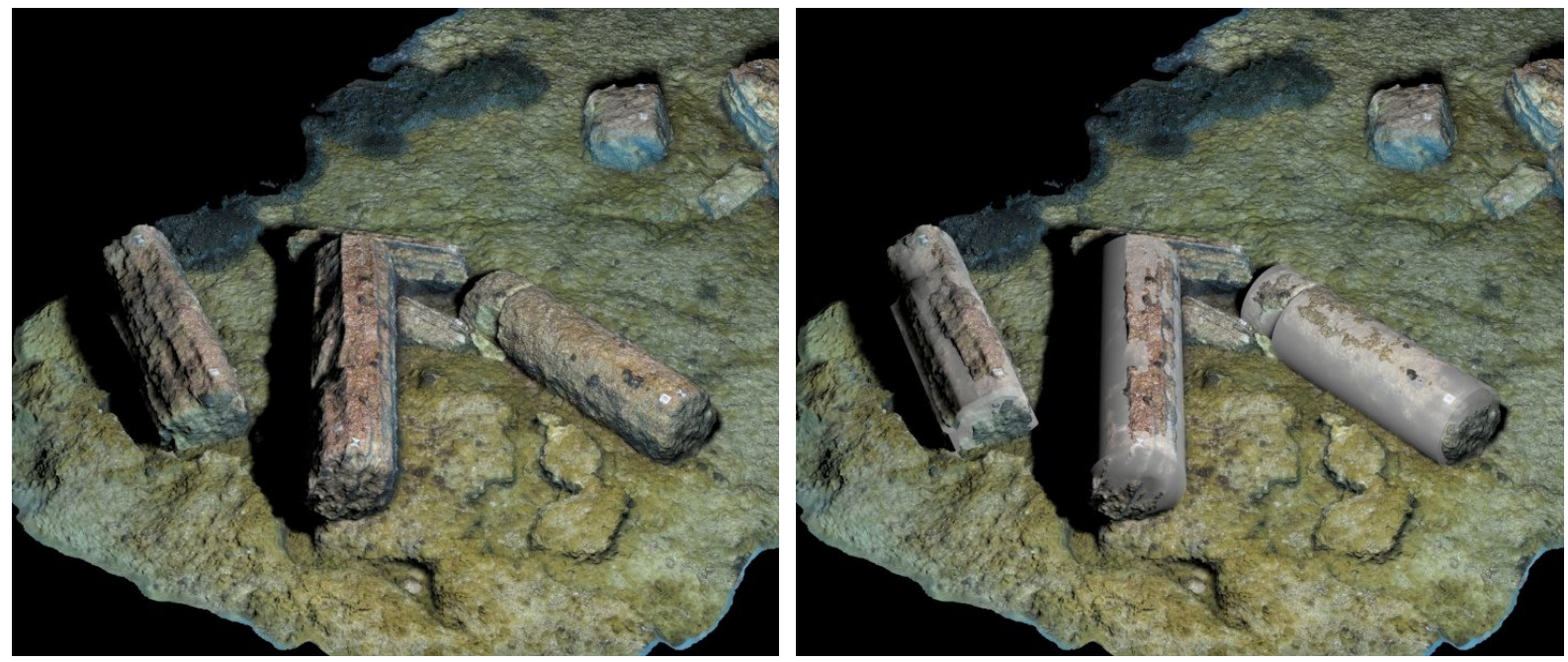

Figure 10. Marzamemi I shipwreck. Original mesh from Photoscan software (on the left) and the mesh integrated with polygonal model texturized (on the right).

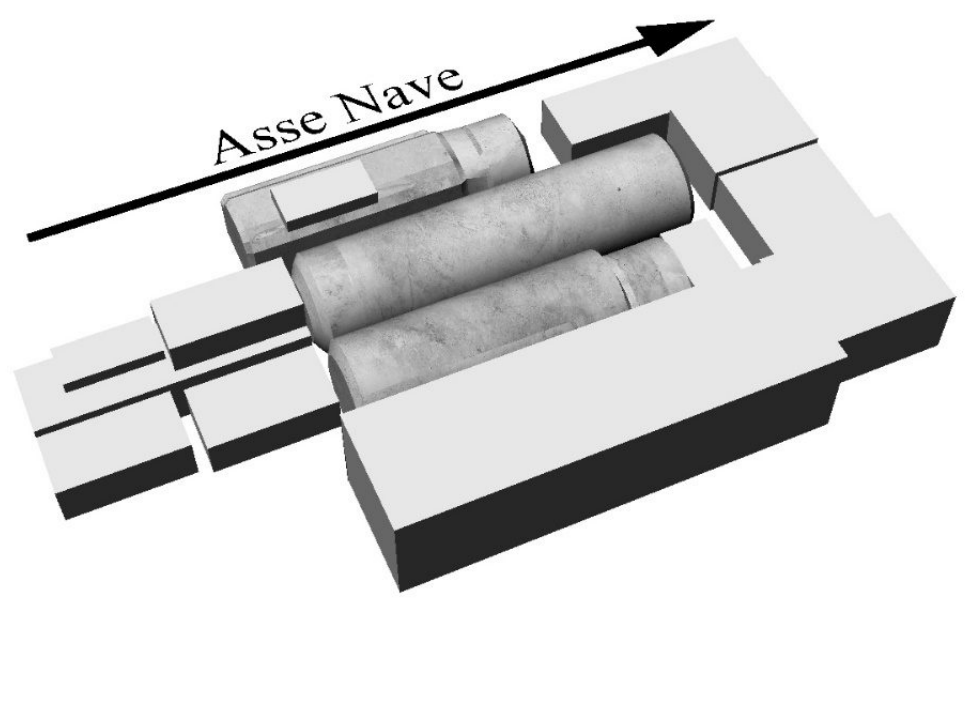

Figure 11. Marzamemi I shipwreck. Reconstruction of the cargo in hypothetic stowage position. (Reconstruction: ing. S. Parizzi, E. Costa).

\section{CONCLUSIONS}

This experience leads to make some different reflections. Regarding survey, the results presented above show how technological advances in recent years have led to multi-image photogrammetry, developing into an inexpensive, rapid (photographic datasets were captured in 1 hour using handheld consumer-grade cameras operated by archaeologically trained scuba divers) and accurate method for recording of underwater archaeological features and presenting a largely automatic approach in processing. Furthermore multi-image photogrammetry can be used to perform analysis in ways 
that were previously unavailable to marine archaeologists.

Regarding these described experience, much more have to be done in the field of "on site" calibration to guarantee a better accuracy. The camera calibration has to be carried out in situ because of the extremely varying chemical and physical properties of water (salinity, temperature, density, etc.), the medium the optical rays move across. But within the very short period as required in the underwater photogrammetric survey these parameters, once estimated, are invariant so they can be used for the photogrammetric processing. As several other experiences, a 3D frame is to be designed to provide the known points for the orientation of the photograms and to execute the cameras calibration.

From the perspective of representation, 3D reconstruction offers many opportunities for the documentation of underwater cultural heritage, thanks to the possibility to de-materialize the tangible heritage, so that it can be enjoyed and studied without any constraint given by the marine environment ${ }^{30}$. The $3 \mathrm{D}$ model, allows an immediate reading of the information about shape and dimensions of the cargos of marble blocks; the virtual navigation allows to perceive the whole complex, which is impossible to clearly recognize in the underwater environment, and some virtual hypothesis of the stowage of blocks can be done.

In addition to the capability of rendering the excavation by producing drawings or orthophotos and measuring 3D models, the management and exploration of digital models with stereoscopic display systems (such as virtual reality headset as Oculus) enable the possibility to explore deep underwater archaeological sites that can be inaccessible by not trained scuba divers. Interactive multimedia products aimed at promoting knowledge of underwater cultural heritage to a wide public (scholars, students, tourists, etc.), made from the collection of images produced (renderings, texts, reproductions of iconography) starting from the reality based survey and structured in an interactive visualization.

Virtual and augmented reality can offer to archaeologists new knowledge on data collected by accurate photogrammetric surveys concerning the finds identified on the site as well as the seabed itself, offering new and innovative ways to interact with these data.

\section{ACKNOWLEDGEMENTS}

We want to thank the Superintendent of the Soprintendenza del Mare, Sebastiano Tusa, for the permissions to dive on the sites and Nicolò Bruno for the collaboration in the organization of the missions. The team of Ca' Foscari University included the photographer Duilio Della Libera.

\section{REFERENCES}

[1] Green J., [Maritime Archaeology: a technical handbook], London, (1990).

[2] Hohle, J., "Reconstruction of the underwater object", Photogrammetric engineering \& Remote sensing, PE\&RS Archives, September 1971, 949-954 (1971).

[3] Bass, G.F., [Archaeology underwater], Thames and Hudson, London, (1966).

[4] Capra, A., "Non-conventional system in underwater photogrammetry", International Archives Photogrammetry and Remote Sensing, XXIX-B5, 234-240 (1992).

[5] Leatherdale, J.D., Turner, D.J., "Operation al experience in underwater photogrammetry", ISPRS Journal of photogrammetry and remote sensing, 46, 104-112 (1991).

[6] Green J., [Maritime Archaeology: a technical handbook], $2^{\text {nd }}$ ed, London, (2004).

[7] Green, J., S. Matthews, and T. Turanli. "Underwater Archaeological Surveying Using PhotoModeler, VirtualMapper: Different Applications for Different Problems", The International Journal of Nautical Archaeology, IJNA 31, 283-92 (2002).

[8] Canciani, M., Gambogi, P., Romano, F.G., Cannata, G. and Drap, P., "Low cost digital photogrammetry for underwater archaeological site survey and artifact insertion. The case study of the Dolia wreck in Secche della Meloria-Livorno-Italia”, Int. Arch. Photogramm. Remote Sens. Spatial Inf. Sci., XXXIV- 5/W12, 95-100 (2003).

[9] Bass G.F.. "New techniques of archaeology and greek shipwrecks of the sixth and fifth centuries BC", PAPS 150, 1-14 (2006).

[10] Drap, P., Seinturier, J.,Scaradozzi, D., Gambdogi, P., Long L., Gauch, F. "Photogrammetry for virtual exploration of underwater archeolgical sites” Int. Arch. Photogramm. Remote Sens. Spatial Inf. Sci., XXXVI- 5/C53 (2007). 
[11]De Reu J., De Smedt P., Herremans D., Van Meirvenne M., Laloo P., De Clercq W., “On introducing an imagebased 3D reconstruction method in archaeological excavation practice" Journal of Archaeological Science, 41, 251262 (2014).

[12] Drap, P., Merad, D., Seinturier, J., Mahiddine, A., Peloso, D., Boi, J.-M., Long L., Chemisky, B., Garrabou, J., "Underwater photogrammetry for archaeology and marine biology: 40 years of experience in Marseille, France", Digital Heritage International Congress (DigitalHeritage), vol. 1, 28 oct - 1 nov 2013, Marseille France, (2013).

[13] McCarthy, J., Benjamin, J., "Multi-image photogrammetry for underwater archaological site recording: an accessible, diver-based approach", Journal of maritime archaeology, 03/2014. Available from: http://www.researchgate.net/publication/260795817_Multi_Image_Photogrammetry_for_Underwater_Archaeologic al_Site Recording_An_Accessible_Diver-Based_Approach, (2014).

[14] Menna F., Nocerino E., Del Pizzo S., Ackermann S., Scamardella A., "Underwater photogrammetry for 3D modeling of floating objects: The case study of a 19-foot motor boat", in Rizzuto E., Guedes Soares C. [Sustainable Maritime Transportation and Exploitation of Sea Resources], Crc Press, 537-544 (2011).

[15] Skarlatos, D., Demestiha, S., Kiparissi, S., "An "open" methods for 3D modeling and mapping underwater archaeological sites", International Journal of Heritage in the digital era, Vol. 1, no. 1, March 2012. Available from: http://multi-science.metapress.com/content/q603163q0k861431/, (2012).

[16]Eric, M., Kovacic, R., Berginc, G., Pugelj, M., Stopinsek, Z., Solina, F., “The impact of the latest 3D technologies on the documentation of underwater heritage sites", Proceedings of the 2013 Digital Heritage International Congress 2013, 28 Oct - 1 Nov, Marseille, France: IEEE, 2013, vol. 2, (2013).

[17] Henderson J., Pizarro O., Johnsons-Roberston M. and Mahon I., "Mapping Submerged Archaeological Sites using Stereo-Vision Photogrammetry", The International Journal of Nautical Archaeology, IJNA 42.2, 243-56 (2013).

[18] Demesticha, S., Skarlatos, D., Neophytou, A., "The 4th century B.C. shipwreck at Mazotos, Cyprus: new techniques and methodologies in the 3D mapping of shipwreck excavations", Journal of Field Archaeology. 39.2, 134-150 (2014).

[19] Costa, E., Beltrame, C., Guerra, F., "Potentialities of 3D reconstruction in Maritime Archaeology", CAA 2014 21st Century Archaeology. Concepts, methods and tools, Proceedings of the 42nd Annual Conference on Computer Applications and Quantitative Methods in Archaeology, 549-556 (2015).

[20] Kapitaen, G., "Schiffsfrachten antiker Baugesteine und Architekturteile vor den Kuesten Ostsiziliens", Klio 39, 276318 (1961).

[21] Remondino, F., Spera, MG., Nocerino, E., Menna, F., Nex, F., "State of the art in high density image matching", Photogramm Rec 29, 144-166 (2014)

[22] Remondino, F., Del Pizzo, S., Kersten, P.T., Troisi, S., "Low-cost and open-source solutions for automate image orientation-a critical overview", Lect. Notes Comput. Sci. 7616, 40-54 (2012).

[23] Balletti, C., Guerra, F., Scocca, V., and Gottardi, C., "3d integrated methodologies for the documentation and the virtual reconstruction of an archaeological site", Int. Arch. Photogramm. Remote Sens. Spatial Inf. Sci., XL-5/W4, 215-222, doi:10.5194/isprsarchives-XL-5-W4-215-2015 (2015).

[24] Capra, A., Dubbini, M., Bertacchini, E., Castagnetti, C., and Mancini, F., "3D reconstruction of an underwater archeological site: comparison between low cost camera”, Int. Arch. Photogramm. Remote Sens. Spatial Inf. Sci., XL-5/W5, 67-72, doi:10.5194/isprsarchives-XL-5-W5-67-2015 (2015).

[25] Agrafiotis, P. and Georgopoulos, A., "Camera costant in the case of two media photogrammetry", Int. Arch. Photogramm. Remote Sens. Spatial Inf. Sci., XL-5/W5, 1-6, doi:10.5194/isprsarchives-XL-5-W5-1-2015, 2015.

[26] Troisi, S., Del Pizzo, S., Gaglione, S., Miccio, A., and Testa, R. L., "3D models comparison of complex shell in underwater and dry environments”, Int. Arch. Photogramm. Remote Sens. Spatial Inf. Sci., XL-5/W5, 215-222, doi:10.5194/isprsarchives-XL-5-W5-215-2015, 2015.

[27] Lavest, J. M., Rives, G., Lapreste, J. T., "Dry camera calibration for underwater applications", Machine Vision and Applications, Vol. 13, 245-253 (2003).

[28]Drap, P., "Underwater Photogrammetry for Archaeology", Special applications of photogrammetry, http://www.intechopen.com/books/special-applications-of-photogrammetry/underwater-photogrammetryforarchaeology (2012).

[29]Rule, N., "The Direct Survey Method (DSM) of underwater survey and its application underwater", The International Journal of Nautical Archaeology, IJNA, 18.2, 157-162 (1989).

[30]Bruno, F., Lagudi, A., Gallo, A., Muzzupappa, M., Davidde Petriaggi, B., and Passaro, S., "3D documentation of archeological remains in the underwater park of Baiae”, Int. Arch. Photogramm. Remote Sens. Spatial Inf. Sci., XL5/W5, 41-46, doi:10.5194/isprsarchives-XL-5-W5-41-2015 (2015). 